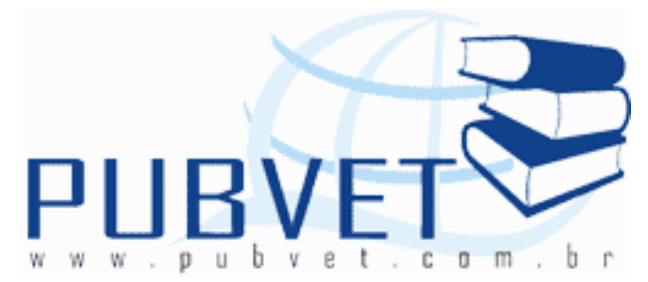

PUBVET, Publicações em Medicina Veterinária e Zootecnia.

\title{
O aspecto qualidade em duas cooperativas do Estado do Rio Grande do Sul
}

\section{César Augustus Winck ${ }^{1}$, Valdecir José Zonin ${ }^{2}$, Luciana Maria Scarton ${ }^{3}$, Alex Leonardi ${ }^{2}$, João Armando Dessimon Machado ${ }^{4}$}

${ }^{1}$ Doutorando em Agronegócios pelo CEPAN/UFRGS e Professor da UNOESC. cesar.cepan@gmail.com

${ }^{2}$ Doutorando pelo CEPAN/UFRGS - bolsista CAPES

${ }^{3}$ Mestre em Agronegócio pelo CEPAN/UFRGS

${ }^{4}$ Professor Associado da UFRGS.

\section{Resumo}

O leite é um dos principais produtos do agronegócio do Estado do Rio Grande do Sul e grande parte de sua produção e industrialização está vinculada ao cooperativismo. Este artigo aborda o aspecto qualidade da produção em duas cooperativas do Estado, e sua interferência na melhoria dos resultados técnicos e econômicos.

Palavras-chave: Leite, Cooperativismo, Agronegócio

\section{Abstract}

The milk is one of the main products of agribusiness in the State of Rio Grande do Sul and much of its production and industrialization is linked to the cooperative. This article examines the aspect of quality of production 
WINCK, C.A. et al. O aspecto qualidade em duas cooperativas do Estado do Rio Grande do Sul. PUBVET, Londrina, V. 5, N. 32, Ed. 179, Art. 1211, 2011.

cooperatives in two of the state and its interference in the improvement of technical and economical results.

Key-words: Milk, Cooperative, Agribusiness

\section{INTRODUÇÃO}

O Rio Grande do Sul ocupa posição de destaque no que tange à produção de leite no país, sendo o segundo em volume (2.944 milhões de litros/ano) e em produtividade (2.222 litros/vaca) segundo o IBGE (2008), sendo a produção gaúcha uma das mais eficientes do país.

A matriz leiteira do Estado abastece a indústria alimentícia regional e, exporta leite fluido para outros estados, visto que grande parte da produção beneficiada é representada pelo leite UHT, aumentando-se assim, sua vida útil e o tempo de operações no mercado, evidenciando-se assim, as vantagens competitivas do Estado neste mercado, afirmam FINAMORE \& MONTOYA (2007).

Numa abordagem mais abrangente, no que tange a participação do setor leiteiro no PIB gaúcho, FINAMORE \& MONTOYA (2005) apontam que no complexo lácteo, o leite representou $2,5 \%$ do PIB (Produto Interno Bruto) e 6,8\% do PIB relativo ao agronegócio gaúcho no ano de 2005.

Outro ponto importante a destacar diz respeito á tipificação desta produção. Neste sentido importa observar que a agricultura familiar, constituída na sua essência por pequenos produtores rurais, responde segundo PEREIRA (2009), por aproximadamente 98 \% da produção desta origem, representando 74.000 Unidades Familiares no Estado. Assim, este setor é responsável pela ocupação de elevado número de famílias no meio rural, reproduzindo significativa renda mensal às famílias rurais, que possuem por sua vez, caracterização predominantemente familiar na maior parte das regiões e dos ambientes produtivos, neste setor, no Estado.

PEREIRA (2009) enfatiza que em termos de custo de produção, o leite produzido no Rio Grande do Sul é competitivo nacionalmente, devendo-se este 
WINCK, C.A. et al. O aspecto qualidade em duas cooperativas do Estado do Rio Grande do Sul. PUBVET, Londrina, V. 5, N. 32, Ed. 179, Art. 1211, 2011.

fato a presença de dezenas de cooperativas agrícolas responsáveis pela base de manutenção da oferta de leite no Estado, e mesmo as organizações nãocooperativadas possuem suas estratégias de aquisição de leite por intermédio do setor cooperativo, enfatizando mais uma vez a importância do setor cooperativo gaúcho neste cenário.

\section{MATERIAL E MÉTODOS}

Realizou-se um estudo exploratório em duas cooperativas do Rio Grande do Sul, durante o mês de junho de 2009, a fim de gerar informações acerca da produção em nível de propriedades e de laticínio, através de visitas in loco e entrevistas individuais e não-estruturadas com gestores e funcionários. Para o embasamento teórico da pesquisa, foi desenvolvida pesquisa bibliográfica em diversas fontes de cunho científico, além da análise de relatórios financeiros, técnicos e de gestão das cooperativas estudadas.

\section{RESULTADOS E DISCUSSÃO}

A Cooperativa "A", localizada na região da Serra Gaúcha é a mais antiga em atividade no segmento leite no Rio Grande do Sul, com 98 anos. Possui atualmente (2010) aproximadamente quatro mil cooperados com cerca de 2.800 produzindo leite. Sua capacidade produtiva está em torno de $500 \mathrm{mil}$ litros/dia, distribuídos em: longa vida (65\%), derivados (25\%), pasteurizados (10\%) e seu faturamento chegando em 2008 a 423 milhões de reais.

Com foco na qualidade, na década de 50 buscou a melhoria das suas matrizes leiteiras através da inseminação artificial. Sabendo que o cooperado possui grande parte da responsabilidade pela qualidade, a partir de 1987 organizou-os em núcleos, objetivando reuniões e trocas de idéias, o que facilitou muito a comunicação. Em 1991, a cooperativa " $A$ " visando diferenciarse entre os concorrentes, iniciou um sistema de pagamento pela qualidade do leite, e não somente por volume como era feito até então e como ainda ocorre na maioria dos laticínios. 
WINCK, C.A. et al. O aspecto qualidade em duas cooperativas do Estado do Rio Grande do Sul. PUBVET, Londrina, V. 5, N. 32, Ed. 179, Art. 1211, 2011.

O pagamento pela qualidade funcionou a partir de um sistema de bonificação e pontuação dividido por setores (valor proporcional aos pontos adquiridos pelo produtor que possuía resfriadores, ordenha com piso, mangueira de água encanada), portanto, quanto mais pontos o produtor possuía, mais vantagem ao longo do ano recebia.

A questão da coleta do leite também se tornou prioridade para a cooperativa, já que foi constatado que durante o percurso da propriedade até a unidade de recebimento era onde acontecia a maior parte da contaminação do leite. Nesse sentido, em 1996 o transporte passou a ser realizado com tanques isotérmicos, permitindo assim um controle maior sobre a qualidade do leite e a identificação dos produtores que deveriam ter uma atenção maior em termos de cuidados produtivos.

A preocupação com a qualidade fez com que todos os atores envolvidos com a cooperativa (produtores, funcionários, fornecedores) trabalhassem em prol de uma conquista que chegou em 1999: a certificação ISO 9000. O que na época foi uma estratégia de marketing, atualmente é uma ferramenta de gestão, que auxilia em estratégias de fidelização tanto do cooperado, como na conquista de novos clientes através de diferenciação no mercado.

Com a previsão de crescer $15 \%$ no faturamento em 2010, investe um valor muito pequeno em P\&D (Pesquisa e Desenvolvimento), colhendo dados no mercado somente de forma informal, ou através de empresas parceiras. Mesmo assim, visualiza o mercado exterior no setor de leite em pó, fixando assim parceria com a Cooperativa Central Gaúcha Ltda. (CCGL), detentora de uma unidade de processamento de leite em pó, na perspectiva de aumentar o faturamento, já que considera saturado, o mercado nacional de leite fluido.

A cooperativa se caracteriza por possuir grande parte de seus produtores enquadrados como agricultores familiares, e fornece a estes, assessoria técnica, programas de melhoramento genético e sanitário dos rebanhos, programas de capacitação e fidelização agrícola e auxílio em questões socioambientais. Também mantém políticas para o desenvolvimento 
WINCK, C.A. et al. O aspecto qualidade em duas cooperativas do Estado do Rio Grande do Sul. PUBVET, Londrina, V. 5, N. 32, Ed. 179, Art. 1211, 2011.

profissional de seus funcionários, e participa de atividades sociais que impulsionam a economia da região que está inserida.

A Cooperativa "B", situada na região do Vale do Taquari-RS, completou em 2010, 54 anos de história. Com uma produção diária de 200 mil litros de leite, possui 4.100 cooperados, sendo aproximadamente 1.400 produtores no setor leiteiro.

A industrialização de leite e derivados correspondeu a $25,3 \%$ do faturamento do ano de 2008, enquanto o setor de avicultura faturou 38,85\%, suinocultura $(8,47 \%)$ e rações $(11,46 \%)$. Seu faturamento que foi de $R \$ 141$ milhões em 2002, passou a R\$ 360 milhões em 2008, demonstrando seu potencial de crescimento.

Atualmente (2010) direciona seu o foco ao envase de leite UHT em sache, concorrendo assim com a embalagem tradicional existente no mercado. Por ser um material mais barato, cerca de $\mathrm{R} \$ 0,10$ a menos no custo do produto final em comparação ao leite de "caixinha", a cooperativa afirma conseguir melhorar o pagamento por litro de leite aos produtores, quando comparado ao preço pago pelos concorrentes, e isto aparentemente tem melhorado a fidelização dos cooperados.

A cooperativa oferece a seus cooperados algumas vantagens, em relação a produtores de leite não-cooperados, como por exemplo, auxílio-escola, auxílio-farmácia, bolsas de estudos, e bonificação extra por litro entregue.

Há cinco anos retomou as atividades em laticínios e já possui a $4^{a}$ marca mais lembrada do setor no Estado. Mesmo sem um departamento de Marketing instituído, e o de P\&D estar funcionando a pouco mais de um ano, existe incentivo à inovação e lançamento de produtos diferenciados, como por exemplo, estudos para o lançamento de um "refrigerante" a base de leite.

Esta cooperativa não possui certificação ISO, e incentiva seus colaboradores através do Programa de Participação nos Resultados (PPR) através de reuniões mensais de motivação. A cooperativa esta focada cada vez mais na qualidade oferecida aos consumidores e na expansão de sua indústria leiteira visando seu desenvolvimento e de seus cooperados. Buscando ser 
WINCK, C.A. et al. O aspecto qualidade em duas cooperativas do Estado do Rio Grande do Sul. PUBVET, Londrina, V. 5, N. 32, Ed. 179, Art. 1211, 2011.

competitiva também no mercado externo, tem exportado leite longa vida para o mercado africano.

O incentivo e a bonificação financeira por qualidade do leite, oferecida aos produtores pelas cooperativas estudadas, demonstra a preocupação pelo reconhecimento dos esforços dos cooperados, e apresenta um quadro inovador no mercado lácteo nacional, visto que são poucas as empresas do Brasil, que se utilizam deste fator para diferenciar o leite nas propriedades.

\section{CONSIDERAÇÕES FINAIS}

As duas cooperativas têm se adequado as exigências legais e sanitárias, atendendo os consumidores com produtos inovadores e de qualidade, buscando o diferencial mercadológico no concorrido mercado lácteo nacional e internacional. A tendência atual de compor um mix de produtos completo e diferenciado mercadologicamente também pode ser percebida, além da preocupação com o fator competitividade e fidelização dos produtores cooperados, através do pagamento pela melhoria da qualidade do leite produzido.

Ambas têm demonstrado visão estratégica, ação mercadológica e respeito pelos seus pares de forma a diferenciarem-se no mercado, o que valida à ação cooperativa como forma de inclusão dos produtores rurais por elas atendidas.

\section{LITERATURA CONSULTADA}

FINAMORE, E.B. \& MONTOYA, M.A. Dimensão Econômica do Complexo Lácteo Gaúcho. In: International Pensa Conference On Agri-Food Chain/Networks Economics And Management, 5.; Ribeirão Preto. Procedings... Ribeirão Preto: FEA/USP. 2005.

FINAMORE, E. B. \& MONTOYA, M.A. Manual de cálculo do preço de referência do leite no RS. Passo Fundo: Ed. UPF, 2007.

IBGE - Instituto Brasileiro de Geografia e Estatística. Produção Agrícola Municipal, 2008. Disponível em http://www.ibge.gov.br. Acesso em 20/06/2010.

PEREIRA, F.I. Modelagem da gestão de custos interorganizacionais na cadeia agronegocial láctea. Revista del Instituto Internacional de Costos, Braga-Portugal, v.5, n.2, p. 401420, 2009. 